\title{
22. Journalism With Machines? From Computational Thinking to Distributed Cognition
}

\author{
Eddy Borges-Rey
}

\begin{abstract}
This chapter reflects on the ways news automation increasingly distributes journalistic knowledge and thought processes.

Keywords: automated journalism, distributed cognition, computational thinking, extended mind, databases, machine learning
\end{abstract}

Imagine you are a journalist in the not so distant future. You are working on a story, and in order to get the insight you are looking for, you ask your conversational agent (who you affectionately call Twiki) to stitch together over 15 anonymized databases. Given the magnitude and complexity of the fused data sets, visualization software is too rudimentary to isolate the anomalies you are searching for. So, using your brain implant, you plug into the system and easily navigate the abstraction of the data sets. Although, individually, each redacted data set is effective in protecting the identity and the personal data of the people listed, when combined, you are able to infer the identity of some top-profile individuals and put into context their personal data. Realizing the potential legal implications of revealing the names and the data attached to them, you ask Twiki to run a neural network to determine whether disclosing this information has ethical or legal implications. The network runs a " + +" number of simulations of virtual journalists making decisions based on a number of codes of ethics and regulatory frameworks. Whilst this runs in the background, you manage to isolate a few outliers and identify a couple of interesting trends. Since you want to make sure the anomalies have something to add to the story, and are

Bounegru, L. and J. Gray (eds.), The Data Journalism Handbook: Towards a Critical Data Practice. Amsterdam: Amsterdam University Press, 2021 DOI 10.5117/9789462989511_CH22 
not simply errors, you ask Twiki to check through archival historic records to see if the outliers coincide with any major historical event. In addition, you ask Twiki to run a predictive model to calculate the likelihood that the identified trends will persist for the foreseeable future, thus triggering worrying implications.

This brief, fictional introduction is based on a fascinating conversation I had with former Times data journalist Nicola Hughes a few years ago. Although the scene it describes could well have come out of Philip K. Dick's "The Minority Report," it actually refers to a range of tools and techniques that are either already available and widely used, or in rapid development. More importantly, it also refers to a kind of journalistic workflow and professional mindset emerging in newsrooms, in a world where journalists are increasingly engaging with data and computation is becoming indispensable.

These recent changes reflect how historically, every time a major technological innovation has been introduced into the news production workflow, news reporting itself has not only been disrupted and consequently transformed, but journalists' thought processes and working professional ideals have invariably been modified.

Today, as we move beyond the era of big data to the era of artificial intelligence (AI) and automation, principles and working practices that hail from computing and data science become ever more pervasive in journalism. As Emily Bell, Founding Director of the Tow Center for Digital Journalism at Columbia University, puts it:

Every company in every field, and every organization, whether they are corporate or public sector, will have to think about how they reorient themselves around AI in exactly the same way that 20 years ago they had to think about the way they reoriented themselves around web technologies. (Bell, personal communication, September 7, 2017)

In this context, this chapter reflects on the ways journalists who work closely with data and automated processes internalize a range of computing principles, that on the one hand augment their journalistic abilities, and on the other have begun to modify the very cornerstone of their journalistic approaches and ideals.

The chapter, thus, explores a range of theoretical concepts that could serve as a framework to envision journalistic cognition in an environment of pervasive computation. I adopt the notion of extended cognition to stimulate further discussion on the ways in which journalistic cognition is nowadays dependent on (and therefore distributed across) the machines 
used to report the news. Through this discussion I hope to encourage future work to investigate the role of computation in journalistic situations, including empirical work to test and further specify the concept of distributed journalistic cognition. This line of inquiry could be particularly useful for professional journalists who want to be aware of, and engage with, the changes journalism is likely to experience if datafication and automation become ubiquitous in news production.

\section{Computational Thinking}

In an attempt to trace the historical meaning of the concept of computation, Denning and Martell (2015) suggest that "[c]omputation was taken to be the mechanical steps followed to evaluate mathematical functions [and] computers were people who did computations." In the 1980s, however, the concept was more frequently associated with a new way of doing science, thus shifting its emphasis from machines to information processes (Denning \& Martell, 2015).

This shift in emphasis is critical for my argument, as it aligns the ultimate goals of news reporting and computation: Journalism is also about managing information processes - in very general terms, the journalist's job consists of streamlining the flow of information, curating it and packaging it in a format that is palatable to an audience. Here, I would argue that the pervasiveness of a computational mindset in news reporting is partially due to the similarities that exist between both professional practices.

Both computing and journalism are formulaic, about solving problems and require syntactical mastery. Wing (2008) remarks that "[o]perationally, computing is concerned with answering 'How would I get a computer to solve this problem?"' (p. 3719), and this requires a relatively high level of computational thinking. As computation becomes a norm in newsrooms, computational thinking is employed by an increasing number of journalists to approach data stories. Bradshaw, for instance, argues that computational thinking "is at the heart of a data journalist's work," enabling them "to solve the problems that make up so much of modern journalism, and to be able to do so with the speed and accuracy that news processes demand" (Bradshaw, 2017).

Computational thinking is the reflexive process through which a set of programmatic steps are taken to solve a problem (Bradshaw, 2017; Wing, 2006, 2008). Wing contends that "the essence of computational thinking is abstraction" and that "in computing, we abstract notions beyond the physical dimensions of time and space" (Wing, 2008, p. 3717) to solve problems, 
design systems and understand human behaviour (Wing, 2006). The author argues that in order to answer the question "How would I get a computer to solve this problem?" computing professionals have to identify appropriate abstractions (Wing, 2008, p. 3717) which are suitable for designing and implementing a programmatic plan to solve the problem at hand.

Since the introduction of automation technologies in newsrooms, journalists working with computing professionals have faced a similar question: "How would I get a computer to investigate or write a news story to human standards?" Gynnild proposes that the infusion of computational thinking into professional journalism challenges the "fundamental thought system in journalism from descriptive storytelling to abstract reasoning, autonomous research and visualization of quantitative facts" that equips journalists with "complementary, logical and algorithmic skills, attitudes, and values" (Gynnild, 2014).

Of course, this is not to say that the idea of "computational" abstraction is a new one to journalists. In fact, journalists working on beats like finance, business, real estate or education exert abstraction on a daily basis to understand complex dynamics such as market performance, stock returns, household net worth, etc. And interestingly, as Myles (2019) remarks, contrary to expectations that automation would free up journalists from onerous tasks, it has introduced a range of new editorial activities not previously performed by journalists. For instance, he explains that the introduction of image recognition into the workflow of the Associated Press has seen journalists and photographers having to engage with tasks traditionally associated with machine learning, like labelling of training data, evaluation of test results, correcting metadata or generating definitions for concepts (Myles, 2019).

\section{Cognitive Projection and Extended Creativity}

So far, I have argued that journalists who, as part of their job, have to engage with the computational problems introduced by news automation, see their workflows and editorial responsibilities transformed. The Wall StreetJournal, for instance, recently advertised for positions such as Machine Learning Journalist, Automation Editor and Emerging Processes Editor, all associated with the expansion of AI and automation. As a result of these kinds of infrastructural expansions, and the subsequent diversification of editorial responsibilities prompted by them, journalists often find themselves asking questions that project them into the shoes of a machine that has to think and perform like a journalist. An interesting paradox, which brings equally interesting challenges. 
This idea of projection, I believe, is becoming prevalent in news automation. Take, for instance, the quintessential journalistic endeavour: Writing a news story. If we deconstruct the process, in general terms, journalists have to use their creativity to put together an account of events that engages and/ or informs the public. The question, then, is: How do I get a machine to write news that reads as if it were written by a human reporter? Journalists and technologists have collaborated over the last five years to project themselves, in an attempt to solve this question. A good example, on this front, is the implementation of natural language generation (NLG) technologies to automate the production of news stories. But counter to what we could expect, the process still involves human reporters writing templates of news stories, which contain blank spaces that are subsequently filled in by automation software using a database. This process, which has been quite successful in news organizations such as the Associated Press, and in RADAR, a collaboration between the Press Association and Urbs Media, seeks to augment the speed and scale of the news production operation in areas such as sports, company earnings and local news.

Creativity within this realm takes a new form, in which coder-journos have had to rethink storytelling as a machine that decodes and recodes the news-writing process. Instead of discerning which interview would better substantiate an argument or what words would make for a stronger headline, the goal has shifted to choosing which configuration of conditional statements would be more efficient in making the automated system decide which headline would appeal more effectively to the audience of the news organization where it functions. Following the principles of human-computer interaction (HCI) and user experience (UX) design, coder-journos have to anticipate the ways users want to engage with automated informational experiences, the potential ways in which they will navigate the different layers of information and the confines of the news piece. Wheeler (2018), conceptualizing the notion of extended creativity, explains that there are cases of intellectual creation in which "the material vehicles that realize the thinking and thoughts concerned are spatially distributed over brain, body and world." The concept of extended creativity then works well as a framework to explicate the idea that the mind of a journalist working with data and automation now functions in close connection with a series of automations, spanning into a series of Python libraries, Jupyter Notebooks, data sets, data analytics tools and online platforms. This dynamic consequently brings a series of additional challenges worthy of attention.

For example, Mevan Babakar, head of automated fact-checking at Full Fact, explains that one of the challenges they face with their automated 
fact-checker is context. She uses as an example the claim of former UK prime minister Theresa May that her government allocated more resources to the National Health Service (NHS) than the opposition Labour Party promised in their manifesto. And although the claim was fact-checked as accurate, for it to be meaningful and useful to the public, it needs to be understood within a wider context: The allocation was not enough for the NHS to perform efficiently (Babakar, personal communication, August 16, 2018). Therefore, as automated systems are not yet capable of making such contextual connections between sources of information, Babakar and her team have to resort to questions like "How do I get an automated fact-checker to understand the nuances of context?"

\section{Journalistic Distributed Cognition}

To conclude, I would like to further explore the idea of a journalistic distributed cognition and the questions it raises. Anderson, Wheeler and Sprevak (2018) argue that as computers become pervasive in human activity, cognition "spread[s] out over the brain, the non-neural body and ... an environment consisting of objects, tools, other artefacts, texts, individuals, groups and/or social/institutional structures." In journalism, this means that, at present, as journalists use networked software and hardware to augment their capacity to produce news at scale and speed, their cognition becomes distributed across the range of platforms and tools they use. This of course, provides them with unlimited access to most of human knowledge online.

However, this idea of portable knowledge and distributed cognition begs the question of who owns and manages journalists' access to that wealth of knowledge and "free" analytical power. Who enables journalistic distributed cognition? This issue, worthy of deeper discussion, is a thorny one, as we experienced when Google shut down its online data visualization tool Google Fusion Tables. After the closure of the platform, dozens of data journalism projects that had been developed with the tool became unavailable as they were no longer supported by the company.

In this context, as journalists engage with computational dynamics on a daily basis, their computational thinking becomes normalized and facilitates the projection of their cognition into the machines they employ for their daily journalistic routines. As journalistic knowledge becomes distributed, does the same happen to journalistic authority and control? Inexorably, distribution shifts the boundaries that provide journalists with control over their routines and professional cultures, thus impacting on 
their epistemological authority. Looking ahead, as we did in this chapter's fictional introduction, distribution could also create an array of associated risks, once journalists begin to delegate important ethical considerations and decisions to machines. It is important then, that the infrastructure they use to distribute their cognition is open, and available for public scrutiny, if the cornerstone ideals of journalism are to be preserved in the age of data and automation.

\section{Works Cited}

Anderson, M., Wheeler, M., \& Sprevak, M. (2018). Distributed cognition and the humanities. In M. Anderson, D. Cairns, \& M. Sprevak (Eds.), Distributed cognition in classical antiquity (pp. 1-17). Edinburgh University Press.

Bradshaw, P. (2017). Computational thinking and the next wave of data journalism. Online Journalism Blog. https://onlinejournalismblog.com/2017/o8/o3/ computational-thinking-data-journalism/

Denning, P. J., \& Martell, C. H. (2015). Great principles of computing. The MIT Press. Gynnild, A. (2014). Journalism innovation leads to innovation journalism: The impact of computational exploration on changing mind sets. Journalism, 15(6), 713-730. https://doi.org/10.1177/1464884913486393

Myles, S. (2019, February 1). Photomation or fauxtomation? Automation in the newsroom and the impact on editorial labour: A case study. [Technology]. Computation + Journalism Symposium 2019, University of Miami.

Wheeler, M. (2018). Talking about more than heads: The embodied, embedded and extended creative mind. In B. Gaut \& M. Kieran (Eds.), Creativity and philosophy (pp. 230-250). Routledge. http://dspace.stir.ac.uk/handle/1893/26296

Wing, J. M. (2006). Computational thinking. Communications of the ACM, 49, 33-35. https://doi.org/10.1145/1118178.1118215

Wing, J. M. (2008). Computational thinking and thinking about computing. Philosophical Transactions of the Royal Society A: Mathematical, Physical and Engineering Sciences, 366(1881), 3717-3725. https://doi.org/10.1098/rsta.2008.0118

\section{About the Author}

Eddy Borges-Rey is an Associate Professor in Digital Journalism and Emerging Media at Northwestern University in Qatar, and a former broadcast journalist. 
